\title{
Theoretical B3LYP Study on Electronic Structure of Contrast Agent Iopamidol
}

\author{
Fatma Genç, ${ }^{1}{ }^{*}$ Sedat Giray Kandemirli ${ }^{2}$ and Fatma Kandemirli ${ }^{3}$ \\ ${ }^{1}$ Department of General Chemistry, Faculty of Pharmacy, University of İstanbul Yeni Yuzyil, Maltepe Mh., \\ Yilanli Ayazma Cd., İstanbul, Turkey \\ ${ }^{2}$ Department of Radiology, Roy Carver College of Medicine, University of Iowa, Iowa City, United States \\ ${ }^{3}$ Department of Biomedical Engineering, Faculty of Engineering and Architecture, University of Kastamonu, \\ Kuzeykent 37150, Kastamonu, Turkey \\ *Corresponding author: E-mail: ftmgenc@yahoo.com
}

Received: 07-01-2020

\begin{abstract}
Nonionic low-osmolar contrast agents are thought about safe for intravenous or intra-arterial administration. Iopamidol is one of the contrast agents used for diagnostic clinical computed tomography $(\mathrm{CT})$ protocols last four decades years. The molecular structure of Iopamidol was calculated by the B3LYP density functional model with the LANL2DZ basis set by the Gaussian program. The natural bond orbital analysis in terms of the hybridization of atoms and the electronic structure of the title molecule have been analyzed by using the data obtained from the quantum chemical results. First-order hyperpolarizability ( $\beta$ tot), the dipole moment $(\mu)$ and polarizability $(\alpha)$ and anisotropic polarizability $(\Delta \alpha)$ of the molecule have been reported. HOMO and LUMO energies and parameters related to energies, and dipole moment, polarizability and hyperpolarizability show minor dependences on the solvent polarity. The hardness of Iopamidol decreases with increasing solvent polarity. The stability of the Iopamidol contrast agent with the hyper conjugative interactions, charge delocalization has been analyzed using natural bond orbital analysis. In addition, thermodynamic properties were obtained in the range of $200-1000 \mathrm{~K}$.
\end{abstract}

Keywords: Quantum chemical calculations; DFT; B3LYP; lopamidol; gaussian program; electronic structure.

\section{Introduction}

Iodinated X-ray contrast agents (ICM) are often used to enable the medical imaging of soft tissues like organs and blood vessels. ${ }^{1}$ The nonionic, water-soluble, low-osmolar contrast agents such as Iopamidol with the 1-N,3-N-bis(1,3dihydroxypropan-2-yl)-5-[[(2S)-2-hydroxypropanoyl]amino]-2,4,6-triiodobenzene-1,3-dicarboxamide IUPAC name is widely used for intravascular administration., ${ }^{2,3}$ It has very wide diagnostic applications, including the central nervous system, the cardiovascular apparatus, and the urinary tract. ${ }^{4}$ Iopamidol, a clinically approved X-Ray contrast agent, exhibits high water solubility and low toxicity. ${ }^{4,5}$ For this reason, it can be safely administered intravenously at very high doses like $400 \mathrm{mg} / \mathrm{ml} .{ }^{4}$ This contrast agent was eliminated through the kidneys with a half-life of 2 hours. ${ }^{2}$

The molecule of Iopamidol contains a high number of mobile protons on amide and alcohol moiety exchang- ing with water. This contributes to a reduction in the MR signal density of the water proton. So, Iopamidol commonly used for CT, may be also considered as a contrast agent for Magnetic resonance imaging (MRI) applications. ${ }^{4}$

The geometry, dipole moment, polarizability, hyperpolarizability, and other molecular properties can be affected by the polarity of the solvent due to variable interactions with the highest occupied and lowest unoccupied molecular orbitals (HOMO-LUMO) ${ }^{6,7}$ and so the polarity of the solvent can influence the stability and reactivity of the molecule. ${ }^{8}$ They can be obtained by quantum chemical calculation without laboratory measurements, thus saving time and equipment, reducing safety and disposal concerns. So, investigation of the theoretical properties of the molecules has recently attracted the attention of scientists and quantum chemical calculation has been widely used to study reaction mechanisms. ${ }^{9}$ 
Bellich et all discussed the structure of Iopamidol for three different crystalline phases. In the anhydrous and monohydrate crystal forms, they reported that Iopamidol molecules are shown conformation of the long branches emerging from the triiodobenzene ring, while the pentahydrate phase had anti-conformation. IR and Raman spectroscopic studies, conducted in conjunction with quantum chemical calculations on three crystal forms, revealed that distinctly different spectral properties can be attributed, in particular, to different molecular structures. ${ }^{10}$

The Density Functional Theory (DFT) calculations eventually lead to a good understanding of molecular properties and a detail of the molecular characteristics and interactions. ${ }^{8}$ Thermodynamic properties such as enthalpy, entropy, and Gibbs free energy are important to understand the stability of molecules at different temperatures and pressures, which can be easily explained using DFT with the Gaussian 03 program. ${ }^{11,12}$

DFT has recently gained popularity as a cost-effective general procedure for studying the physical properties of molecules. Unlike the Hartree-Fock theory, DFT gives a good electron correlation through electron density functions in the self-consistent Kohn-Sham procedure and complex operations. Descriptions for systems requiring electron correlation in the traditional ab initio approach is, therefore, a cost-effective and reliable method. ${ }^{13,14,15}$

Descriptors such as Chemical hardness, chemical potential, polarizability, and softness known as global reactivity descriptors based on density functional theory have found great utility in field selectivity as well as in predicting the reactivity of atoms and molecules, therefore this work presents the quantum chemical studies of the effects of solvents on molecular properties of Iopamidol such as the highest occupied molecular orbital energy $\left(\mathrm{E}_{\mathrm{HOMO}}\right)$, the lowest unoccupied molecular orbital energy $\left(\mathrm{E}_{\mathrm{LUMO}}\right)$, energy gap $(\Delta \mathrm{E})$, electronegativity $(\mathrm{X})$, electron affinity (A), global hardness $(\mu)$, softness $(S)$, ionization potential (I), the fraction of electrons transferred and the total energy $\left(\Delta \mathrm{N}_{\max }\right)$, nucleofugality $\left(\Delta \mathrm{E}_{\mathrm{n}}\right)$ electrofugality $\left(\Delta \mathrm{E}_{\mathrm{e}}\right)$. These molecular properties of Iopamidol were computed by the B3LYP density functional model with the LANL2DZ basis set by the Gaussian program in the gas phase and in solvents (chloroform, acetic acid, ethanol, DMF, DMSO and water). This study was conducted to report the media effect of Iopamidol on dipole moment, polarizability, first-order hyperpolarizability and chemical reactivity, the stability of Iopamidol in different solvent systems and the development of new pharmaceutical and (bio) chemical products derived from Iopamidol.

\section{Theory and Computational Details}

DFT (density functional theory) methods have become very popular in recent years were used in this study. The fundamental base of DFT is the use of electronic den- sity instead of the wave function for calculating the energy constitutes. All calculations were done by GAUSSIAN $09 \mathrm{~W}$ software package, ${ }^{16}$ using the B3LYP functional ${ }^{9}$ and the LANL2DZ basis set. ${ }^{17}$ The B3LYP, a version of the DFT method, uses Becke's three-parameter functional (B3) and includes a mixture of HF with DFT exchange terms associated with the gradient corrected correlation function of Lee, Yang, and Parr(LYP $)^{9}$. The geometry of the Iopamidol contrast agent under investigation was determined by optimizing all the geometrical variables without any symmetry constraints. In solvents with different dielectric constants such as water, DMSO, DMF, ethanol, acetic acid and chloroform, the Solubility on Density Model applied in Gaussian 09 was used for all calculations. The SMD model is highly parameterized, uses the original polarizable continuity model (PCM), and the charge density of the dissolved molecule interacts with the dielectric environment of the solvent via the surface tension at the solvent-solvent boundary.

\section{Results and Discussion}

In the case of electronic response, the main effects caused by the solvent medium ${ }^{18}$ (i) change of wave function due to change in structure perturbing environment, (ii) change of geometric structure (iii) change of response properties, and (iv) altering the dynamics of the excitation processes.

Optimized structure, the highest occupied molecular orbital (HOMO), the lowest unoccupied molecular orbital (LUMO) and electron density of Iopamidol in the gas phase calculated at the DFT/B3LYP level with the LANL2DZ basis set was given in Figure 1. As seen from Figure 1, HOMO and LUMO are formed from mainly benzene ring and iodine group attached to benzene ring.

A large $\mathrm{E}_{\mathrm{HOMO}}-\mathrm{E}_{\mathrm{LUMO}}$ gap means high kinetic stability and low chemical reactivity due to energetically unfavorable to add electrons to a high-lying LUMO. Meanwhile, a molecule with a small $\mathrm{E}_{\mathrm{HOMO}}-\mathrm{E}_{\mathrm{LUMO}}$ gap is more polarizable, is generally associated with a high chemical reactivity-low kinetic stability and is termed as a soft molecule. ${ }^{19}$ The solvent medium changes the properties of solvated molecules and sometimes significantly affects the dynamics of the processes. Ten molecular orbital energy near $\mathrm{E}_{\mathrm{HOMO}}$ and $\mathrm{E}_{\mathrm{LUMO}}$ to study the photo-physics and kinetic stability of Iopamidol compounds were shown in Figure 2 in different phases such as gas, chloroform, acetic acid, ethanol, DMF, DMSO and water. $\mathrm{E}_{\mathrm{HOMO}}$ and five molecular orbital energy near HOMO of Iopamidol for -6.80 , $-6.85,-6.95,-6.98,-7.10,-7.16 \mathrm{eV}$. $\mathrm{E}_{\mathrm{LUMO}}$ and five molecular orbital energy near LUMO of Iopamidol for gas phase are $-2.19,-1.51,-1.46,-1.12,-0.95,-0.41 \mathrm{eV}$.

The highest occupied molecular orbital (HOMO) which is the outermost orbital filled by electrons and the lowest unoccupied molecular orbital (LUMO) represent-

Genç et al.: Theoretical B3LYP study on Electronic Structure ... 
<smiles>CC(O)C(=O)Nc1c(I)c(C(=O)NC(CO)CO)c(I)c(C(=O)NC(CO)CO)c1I</smiles>

2D

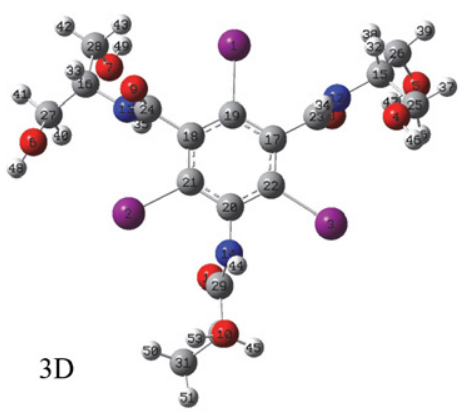

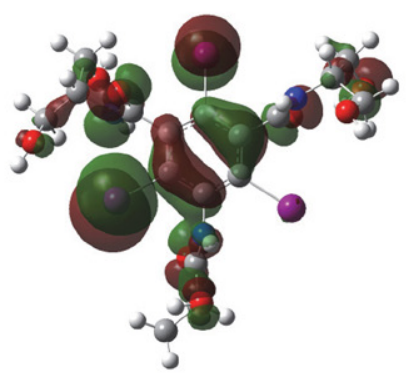

HOMO

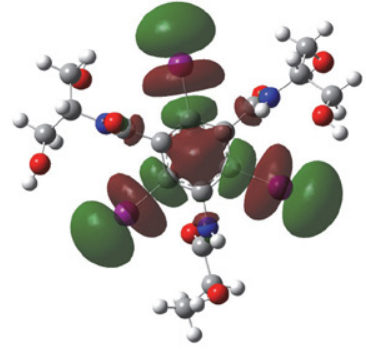

LUMO

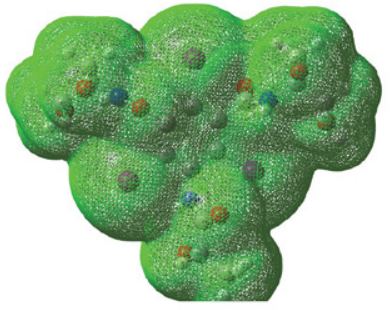

ESP

Figure 1. Optimized Structure, HOMO, LUMO and electron density of Iopamidol

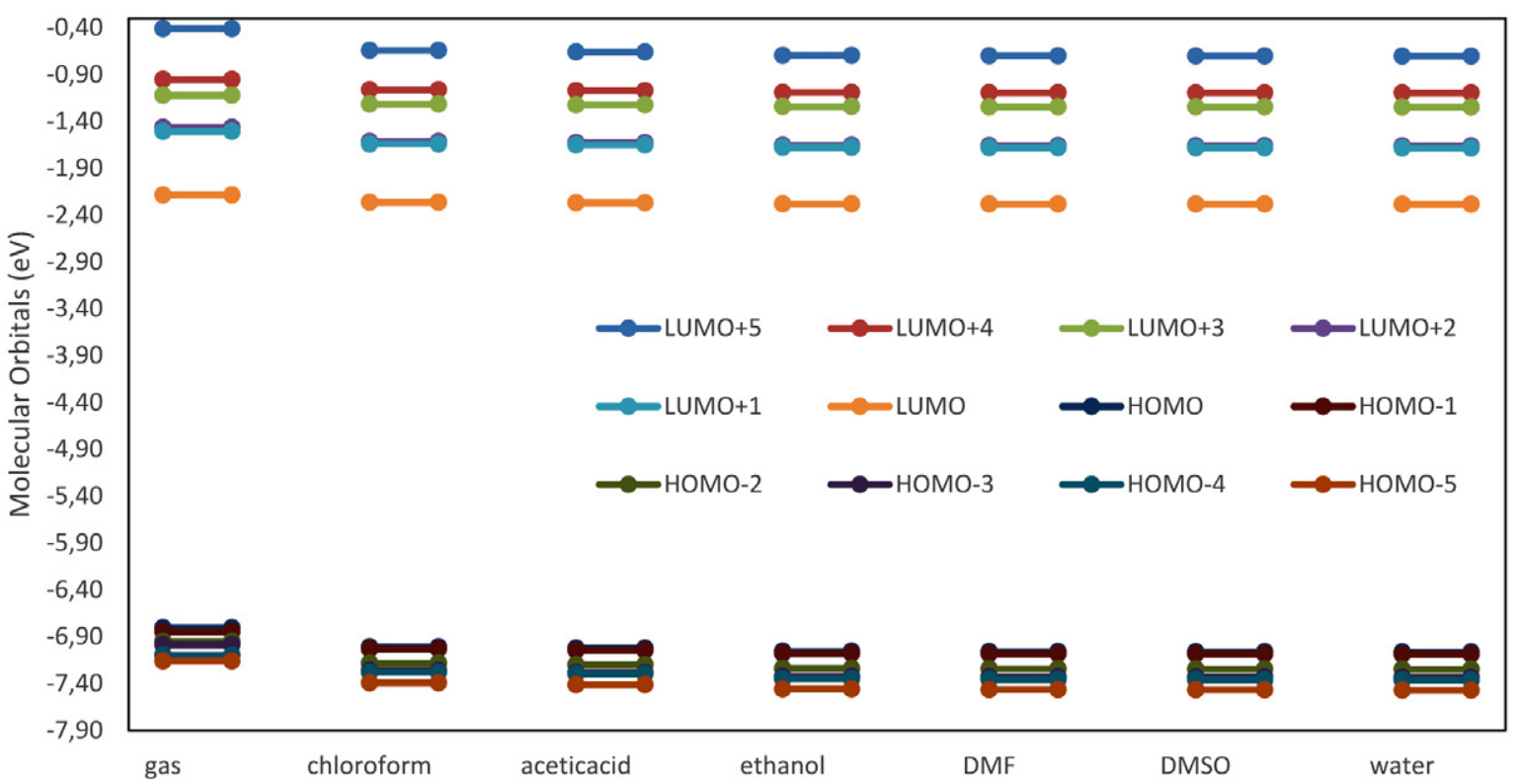

Figure 2. Frontier orbital energies for Iopamido

ing the first empty inner most orbital unfilled by electrons called frontier orbitals are the main orbitals taking part in a chemical reaction. ${ }^{20}$

The HOMO-LUMO energy band gap is a very important parameter for the determination of molecular electrical properties and an indication of molecular chemical stability. The quantum molecular descriptors such as ionization potential, electron affinity, chemical reactivity, kinetic stability, polarizability, chemical hardness and softness, and electro- negativity, electrofugality, nucleofugality can be calculated by using the gap between $\mathrm{E}_{\mathrm{HOMO}}$ and $\mathrm{E}_{\mathrm{LUMO}}$.

$\mathrm{E}_{\mathrm{HOMO}}$ and $\mathrm{E}_{\mathrm{LUMO}}$ values and $\mathrm{E}_{\mathrm{HOMO}}$ and $\mathrm{E}_{\mathrm{LUMO}}$ band gap values, computed with the B3LYP / LANL2DZ level, and additionally, chemical potential, electron affinity, electronegativity chemical hardness, softness and electrophilicity, electrofugality, nucleofugality index parameters, found using the computed HOMO and LUMO energy values, were summarized in Table 1. 
Table 1. Parameters related with $\mathrm{E}_{\mathrm{HOMO}}$ and $\mathrm{E}_{\mathrm{LUMO}}$.

\begin{tabular}{lccccccccccc}
\hline & $\mathbf{E}_{\text {HОмо }}$ & $\mathbf{E}_{\mathbf{L U M O}}$ & $\boldsymbol{\Delta} \mathbf{E}$ & $\mathbf{\eta}$ & $\mathbf{S}$ & $\boldsymbol{\chi}$ & $\boldsymbol{\mu}$ & $\mathbf{\Omega}$ & $\boldsymbol{\Delta} \mathbf{N}_{\max }$ & $\boldsymbol{\Delta} \mathbf{E}_{\mathbf{n}}$ & $\boldsymbol{\Delta} \mathbf{E}_{\mathbf{e}}$ \\
\hline Gas & -6.80 & -2.19 & 4.62 & 2.31 & 0.22 & 4.50 & -4.50 & 4.38 & 1.95 & 1.04 & 10.03 \\
Chloroform & -7.01 & -2.26 & 4.75 & 2.37 & 0.21 & 4.64 & -4.64 & 4.53 & 1.95 & 1.08 & 10.35 \\
Acetic acid & -7.02 & -2.27 & 4.75 & 2.38 & 0.21 & 4.65 & -4.65 & 4.54 & 1.95 & 1.08 & 10.37 \\
Ethanol & -7.06 & -2.28 & 4.77 & 2.39 & 0.21 & 4.67 & -4.67 & 4.57 & 1.96 & 1.09 & 10.43 \\
DMF & -7.06 & -2.28 & 4.78 & 2.39 & 0.21 & 4.67 & -4.67 & 4.57 & 1.96 & 1.09 & 10.43 \\
DMSO & -7.06 & -2.28 & 4.78 & 2.39 & 0.21 & 4.67 & -4.67 & 4.57 & 1.96 & 1.09 & 10.44 \\
Water & -7.06 & -2.29 & 4.78 & 2.39 & 0.21 & 4.67 & -4.67 & 4.57 & 1.96 & 1.09 & 10.44 \\
\hline
\end{tabular}

The highest occupied molecular orbitals (HOMO) and the lowest empty molecular orbitals (LUMO), called boundary molecule orbitals (FMOs), are the main orbitals involved in the chemical reaction. The energy gap formed between HOMO and LUMO indicates the chemical stability of the molecules and is a critical parameter for determining the molecular electrical transport properties as well as the properties of the molecules. The highest HOMO value of $-6.80 \mathrm{eV}$ was found in the gas phase followed by -7.01 , $-7.02,-7.06,-7.06,-7.06,-7.06$ in chloroform, acetic acid, ethanol, DMF, DMSO and water phases indicate that the molecule will be best electron donor in the gas phase. So, it was observed that the negative value of the HOMO increased with the increase of dielectric constants of the solvents. They reported that the inclusion of solvents for Iopamidol causes the HOMO values to become more negative. ${ }^{21}$

The lowest LUMO energy of $-2.29 \mathrm{eV}$ was found to be in water indicating that the molecule will be the best accept electron in water compare to the gas phase and other solvents. The energy gap is used in determining molecular electrical transport properties. The largest HOMO-LUMO gap of $4.78 \mathrm{eV}$ was found in water solvent which implies higher kinetic stability and less chemical reactivity ${ }^{22}$ followed by $4.78 \mathrm{eV}$ and the other studied solvents and found $4.62 \mathrm{eV}$ in the gas phase.

The electronic chemical potential as seen in Equation 1 is defined as the energy changes of the system with respect to the electron number $\mathrm{N}$ at a fixed external potential $\mathrm{v}(\mathrm{r})$, i.e., the potential created by the nuclei. ${ }^{23,}{ }^{24}$ The electronic chemical potential is associated with the feasibility of a system to exchange electron density with the environment at the ground state.

$$
\mu=\left(\frac{\partial E}{\partial N}\right)_{v(r)}
$$

When the finite difference approximation is used the following simple expression is obtained:

$$
\mu \approx-\frac{(I+A)}{2}
$$

Where, I is the ionization potential and A is the electron affinity of an atom or molecule. The ionization poten- tial and the electron affinity can be approached by the frontier HOMO and LUMO energies as by $\mathrm{E}_{\mathrm{HOMO}}$ and as by $\mathrm{E}_{\mathrm{LUMO}}$ according to Koopmans theorem ${ }^{25}$ and KohnSham formalism ${ }^{26}$ within the DFT, as a result, the electronic chemical potential can be expressed as:

$$
\mu \cong\left(\frac{E_{H O M O}+E_{L U M O}}{2}\right)
$$

Accordingly, the electronic chemical potential allows the establishment of the flux direction of the Global Electron Density Transfer ${ }^{27}$ along in a polar reaction. Likewise, in a polar reaction having two molecules, such as A and B, with $\mathrm{uA}<\mathrm{uB}$, the electron density flux will occur from molecule $B$, which has the higher, towards molecule $A$, which has the lower. So, in such a reaction A will act as the electron-acceptor, whereas, B will act as the electron-donor, i.e., the nucleophile. The larger electronic chemical potential difference means global Electron Density Transfer presents a low polar character. Iopamidol molecule in solvent acts as a more electron acceptor molecule than in the gas phase. The chemical potential of the molecule was found to be increased as the dielectric constants of the solvents increased from the gas phase. The chemical potentials of the Iopamidol in chloroform, acetic acid, ethanol, DMF, DMSO, water are $-4.64,-4.65,-4.67,-4.67,-4.67$, $-4.67 \mathrm{eV}$, respectively.

Pearson proposed the hard and soft acids and bases (HSAB) principle in an acid/base reaction.

In 1963, Pearson established a classification of Lewis acids and bases into hard and soft. ${ }^{28-30}$ Within the conceptual DFT, Parr defined, in 1983, a quantitative expression for the chemical hardness, which can be expressed as the changes of the electronic chemical potential of the system with respect to the electron number $\mathrm{N}$ at a fixed external potential $\mathrm{v}(\mathrm{r}) .^{18}$

$$
\eta=\left(\frac{\partial u}{\partial^{2} N}\right)_{v(r)}=\left(\frac{\partial E^{2}}{\partial^{2} N}\right)_{v(r)}
$$

The resistance of a molecule to exchange electron density with the environment is defined as the chemical hardness and when the finite difference approximation is applied, the following simple expression is obtained: 


$$
\eta \approx-\frac{(I-A)}{2}
$$

With the substitution of I by $\mathrm{E}_{\mathrm{HOMO}}$ and $\mathrm{A}$ by $\mathrm{E}_{\mathrm{LUMO}}$ can be expressed as:

$$
\eta \cong\left(\frac{E_{L U M O}+E_{H O M O}}{2}\right)
$$

Also the chemical hardness, chemical potential of the molecule was found to be increased, the chemical softness of the molecule was found to be decreased as the dielectric constants of the solvents increased from gas phase to water and was confirmed to decrease as the dielectric constant of the solvents increased from ethanol to water.

According to Parr and co-workers, global molecular electrophilicity $\left(\omega_{\text {mol }}\right)$ and global molecular nucleophilicity $\left(\varepsilon_{\text {mol }}\right)$ index were defined and they were calculated based on molecular hardness and molecular electronegativity of the studied compounds with the help of the following equations, respectively.

$$
\omega=\frac{\mu^{2}}{2 \eta}
$$

The electrophilicity index measures the property of a molecule to accept electrons. Nucleophile molecule is characterized by a lower value of $\mu, \omega$; and conversely electrophile molecule is characterized by a high value of $\mu, \omega$. Organic molecules having a value of more than 1.5 is classified as strong electrophiles, the value between 0.8 and 1.5 $\mathrm{eV}$ is classified as moderate electrophiles, smaller than 0.8 $\mathrm{eV}$ is said as marginal electrophiles. ${ }^{31}$ Terrier classified high reactivity of the species that he studied as super electrophiles. ${ }^{32}$ So, the electrophilicity index of Iopamidol in the gas phase and different solvents of more than $1.5 \mathrm{eV}$ is classified as super electrophilic. The electrophilicity index of Iopamidol increases with the increase of the dielectric constant of the solvent.

The maximum number of electrons that an electrophile can obtain is given by the following formula. ${ }^{33}$

$$
\Delta N_{\max }=-\frac{\mu}{\eta}
$$

The maximum charge transfer that is completely determined by the electronic chemical potential of the molecule measures the stabilization in energy when the system acquires an additional electronic charge $(\Delta \mathrm{N})$ from the environment. ${ }^{34-36}$ The maximum charge transfer $\Delta \mathrm{N}_{\max }$ to the electrophile means the ability of the system to obtain additional electronic charge from the medium defining the charge capacity of the molecule.

The maximum amount of electronic charge $\left(\Delta N_{\max }\right)$ can define the donor and acceptor electron charge of molecules. The $\Delta N_{\max }<0$ indicates the molecule acts as an electron donor. ${ }^{37}$ In gas and solvent phase, Iopamidol are electron acceptors and can have significant power of electron affinity. The $\Delta N_{\max }$ index of Iopamidol increases as follow: gas < chloroform < acetic acid < ethanol =DMF $=\mathrm{DMSO}<$ water at the B3LYP $/$ LANL2DZ basis set. According to these results, it can be easily predicted that Iopamidol has the biggest $\Delta N_{\max }$ in water for the studied solvents.

Ayers and co-workers ${ }^{38,39}$ have proposed nucleophilic and electrophilic capabilities of a leaving group as nucleofugality $\left(\Delta E_{\mathrm{n}}\right)$ and electrofugality $\left(\Delta E_{\mathrm{e}}\right)$ and defined as follows:

$$
\begin{aligned}
& \Delta E_{n}=E A+\omega=\frac{(\mu+\eta)^{2}}{2 \eta} \\
& \Delta E_{e}=I P+\omega=\frac{(\mu-\eta)^{2}}{2 \eta}
\end{aligned}
$$

Electrofugality values of Iopamidol in gas chloroform, acetic acid, ethanol, DMF, DMSO and water are $10.03,10.35,10.37,10.43,10.43,10.44,10.44$, respectively. As seen from the result electrophilic capabilities of a leaving group for Iopamidol are the highest in the water phase.

The electronic transitions of Iopamidol were calculated by time-dependent DFT in the gas phase Theoretical results were used for the interpretation of experimental absorption bands. The experimental $(\lambda \max )$ and calculated $(\lambda \mathrm{DFT})$ wavelengths of maximum absorption are $241 \mathrm{~nm}^{40}$ and $242.11 \mathrm{~nm}$ which was marked as HOMO-15 $\rightarrow$ LUMO, HOMO-11 $\rightarrow$ LUMO +1 , HOMO-10 $\rightarrow$ LU$\mathrm{MO}+1, \mathrm{HOMO}-7 \rightarrow \mathrm{LUMO}+1, \mathrm{HOMO}-6 \rightarrow \mathrm{LUMO}+1, \mathrm{HO}-$ $\mathrm{MO}-6 \rightarrow \mathrm{LUMO}+2, \quad \mathrm{HOMO}-5 \rightarrow \mathrm{LUMO}+1, \quad \mathrm{HOMO}-2 \rightarrow$ $\mathrm{LUMO}+2$, HOMO-2 $\rightarrow \mathrm{LUMO}+4, \mathrm{HOMO}-1 \rightarrow \mathrm{LUMO}+5$, $\mathrm{HOMO} \rightarrow \mathrm{LUMO}+1, \quad \mathrm{HOMO}-1 \rightarrow \mathrm{LUMO}+4$ transitions which contributions are $-0.20018,0.17061,0.14008$, $-0.12374,0.19838,0.25823,0.21063,-0.11627,0.18419$, $-0.17126,-0.12012,0.12035$.

Electric dipole polarizability which is a measure of the linear response of an infinitesimal electric field $(\mathrm{F})$ and represents second-order variation energy is an important property used in determining the polarizability of a molecule or compound. ${ }^{41}$

$$
\alpha=-\frac{\partial^{2} E}{\partial F_{a} \partial F_{b}}
$$

Where, the $\alpha_{x x}, \alpha_{y y}$ and $\alpha_{z z}$ quantities are the principal values of polarizability tensor. Polarizability $(\alpha)$ which is the measure of distortion of a molecule in an electric field, the anisotropy of the polarizability $\langle\Delta a\rangle$ and Kappa were calculated using the following equation, respectively:

$$
\alpha=\frac{1}{3}\left(\alpha_{x x}+\alpha_{y y}+\alpha_{z z}\right)
$$




$$
\begin{aligned}
& \Delta \alpha=\left[\frac{\left(\alpha_{x x}-\alpha_{y y}\right)^{2}+\left(\alpha_{y y}-\alpha_{z z}\right)^{2}+\left(\alpha_{z z}-\alpha_{x x}\right)^{2}+6\left(\alpha_{x z}^{2}+\alpha_{x y}^{2}+\alpha_{y z}^{2}\right)}{2}\right]^{1 / 2} \\
& \kappa=\frac{\alpha_{x x^{2}}+\alpha_{y y^{2}+\alpha_{z z}^{2}}}{6<\alpha>^{2}}
\end{aligned}
$$

In unsubstituted aromatic molecules, the $\pi$ electrons in a direction perpendicular to the plane do not contribute to the polarizability in a direction perpendicular to the plane, only sigma bonds in the vertical direction contribute to the polarization of the molecules. Since the anisotropy $\mathrm{j}$ becomes zero for the spherical symmetric charge distribution, it gives a measure of the spherical symmetry deviations. The calculated polarizability $\langle\alpha\rangle$, the anisotropy of the polarizability $\langle\Delta \alpha\rangle$ and Kappa for Iopamidol molecules are listed in Table 2.

The variation of $\langle\alpha\rangle$ is in the atomic units and $\langle\Delta \alpha\rangle$ in esu $\left(\times 10^{-24}\right)$ for Iopamidol molecule are given. The result shows that the lowest polarizability and anisotropic polarizability values obtained were 296 au and $21.77 \times$ $10^{-24}$ esu in the gas phase. It was observed that polarizability and anisotropic polarizability increases with an increase in the polarity of the solvents while the kappa decreases as the polarity of the solvents increases.

$$
\begin{aligned}
& \beta_{t o t}=\left(\beta_{x}^{2}+\beta_{y}^{2}+\beta_{z}^{2}\right)^{1 / 2} \\
& \beta_{x}=\beta_{x x x}+\beta_{x y y}+\beta_{x z z} \\
& \beta_{y}=\beta_{y y y}+\beta_{x x y}+\beta_{y z z} \\
& \beta_{z}=\beta_{z z z}+\beta_{x x z}+\beta_{y y z}
\end{aligned}
$$

The, and refer to the components of hyperpolarizability along $x, y$ and $z$ components of molecular dipole moment.

It can be seen from Table 3 , the calculated $\beta$ values of Iopamidol using B3LYP/ LANL2DZ level (the $\beta$ of Iopamidol for gas, chloroform, acetic acid, ethanol, DMF,
DMSO, water) are $1.48 \times 10^{-30}$ esu., $2.55 \times 10^{-30}$ esu., 2.69 $\times 10^{-30}$ esu., $1.87 \times 10^{-30}$ esu., $3.04 \times 10^{-30}$ esu., $3.06 \times 10^{-30}$ esu., $2.94 \times 10^{-30}$ esu., respectively. The first polarizability values obtained using B3LYP/LANL2DZ level for Iopamidol are the largest value in DMSO and the lowest value in gas phase.

\section{Thermodynamic Properties}

The total contribution of the electronic, translational, rotational and vibrational energies to the entropy $(S)$ and heat capacity $(\mathrm{Cv})$, as well as the rotational constants and zero-point vibrational energies (ZPVE) of Iopamidol in the gas phase and different solvents were presented in Table 4.

It can be observed in Table 4 that the specific heat capacity of Iopamidol was found to increase with an increase in the polarity of the solvent except in acetic acid solution. The highest entropy value of $240.311 \mathrm{cal} / \mathrm{mol}$ was found in the gas phase followed by 235.989, 235.189, $234.749 \mathrm{cal} / \mathrm{mol}$ in chloroform, acetic acid, ethanol solution. It was observed that as the dielectric constant of the solvents was increased from chloroform to water the entropy was found to be slightly decreased, while, entropy was found to increase slightly in DMF, DMSO, water. The zero-point vibrational energy (ZPVE) decreases except in acetic acid solution with the increase of dielectric constant.

Based on vibrational analysis at B3LYP/LANL2DZ level, the standard statistical thermodynamic functions: heat capacity $\left(\mathrm{C}^{0} \mathrm{P}, \mathrm{m}\right)$, entropy $\left(\mathrm{S}^{0} \mathrm{~m}\right)$, and enthalpy changes $\left(\mathrm{H}^{0} \mathrm{~m}\right)$,

for the Iopamidol, are obtained from the theoretical harmonic frequencies in gas and solvent phases and presented in Figure 3. It can be observed that these thermodynamic functions are increasing with temperature ranging

\begin{tabular}{|c|c|c|c|c|c|c|c|}
\hline Polarisibility & Gas & Chloroform & Acetic acid & Ethanol & DMF & DMSO & Water \\
\hline$<\mathrm{a}>(\mathrm{au})$ & 296 & 365 & 371 & 386 & 387 & 388 & 389 \\
\hline$\left(<\Delta a>(\mathrm{esu}) 10^{-24}\right.$ & 21.77 & 25.64 & 25.95 & 26.69 & 26.78 & 26.82 & 26.88 \\
\hline$\kappa$ & 0.02646 & 0.02341 & 0.02315 & 0.02254 & 0.02247 & 0.02244 & 0.0224 \\
\hline
\end{tabular}
from 200 to $1000 \mathrm{~K}$ because molecular vibrational intensities increase with temperature. ${ }^{42}$

Table 5, demonstrates the correlation of heat capacity at constant pressure, entropy, enthalpy respectively, for

Table 2. Polarizability $(\langle\alpha\rangle)$, anisotropic polarizability $(\Delta \alpha)$, Kappa $(\kappa)$ of the optimized Iopamidol molecule in the gas phase and different solvents.

Table 3. $\beta \times 10^{-30}$ (esu), $\beta \mathrm{x}, \beta \mathrm{y}, \beta \mathrm{z}$, in (a.u.) components and values calculated using DFT levels of theory for Iopamidol.

\begin{tabular}{lccccccc}
\hline & Gas & Chloroform & Acetic Acid & Ethanol & DMF & DMSO & Water \\
\hline$\beta_{\mathrm{x}}$ & 76.7636 & 173.4901 & 177.5463 & 184.9257 & 185.4881 & 185.5127 \\
$\beta_{\mathrm{y}}$ & -87.2752 & -224.2531 & -240.4815 & 71.3396 & -286.2781 & -288.0864 & 273.0876 \\
$\beta_{\mathrm{z}}^{\mathrm{z}}$ & 57.6274 & 83.6470 & 85.2293 & 88.1287 & 88.4319 & 88.5943 \\
$\beta_{\text {total }}$ & 1.48 & 2.55 & 2.69 & 1.87 & 3.04 & 3.06 & 2.94 \\
\hline
\end{tabular}


Table 4. Thermodynamic properties of the optimized Iopamidol molecule in the gas phase and different solvents.

\begin{tabular}{lccccc}
\hline Positions & $\begin{array}{c}\text { Vibrational } \\
\text { Cv }\end{array}$ & Total & $\begin{array}{c}\text { Rotational } \\
\text { S }\end{array}$ & Vibrational & Total \\
\hline Gas & 117.731 & 123.692 & 38.531 & 155.952 & 240.311 \\
Chloroform & 117.758 & 123.720 & 38.536 & 151.624 & 235.989 \\
Acetic acid & 117.751 & 123.713 & 38.536 & 150.823 & 235.189 \\
Ethanol & 117.760 & 123.722 & 38.536 & 150.384 & 234.749 \\
DMF & 117.764 & 123.726 & 38.536 & 150.414 & 234.779 \\
DMSO & 117.766 & 123.728 & 38.536 & 150.426 & 234.791 \\
Water & 117.769 & 123.731 & 38.536 & 150.453 & 234.818 \\
\hline & Rotational Constants (GHz) & & ZPVE (Kcal/Mol) & \\
\hline Gas & 0.08199 & 0.06561 & 0.04052 & 249.87778 & \\
Chloroform & 0.08118 & 0.06626 & 0.04031 & 249.85006 & \\
Acetic acid & 0.08114 & 0.06629 & 0.04030 & 249.86599 & \\
Ethanol & 0.08109 & 0.06635 & 0.04029 & 249.84713 & \\
DMF & 0.08109 & 0.06636 & 0.04029 & 249.84051 & \\
DMSO & 0.08109 & 0.06636 & 0.04029 & 249.83742 & \\
Water & 0.08108 & 0.06637 & 0.04029 & 249.83212 & \\
\hline
\end{tabular}

For Cv Electronic: 0.000, Translational: 2.981, Rotational: 2.981 For S Electronic: 0.000, Translational: 45.829

Table 5. Correlation of heat capacity, entropy and enthalpy with temperature for Iopamidol molecule

\begin{tabular}{llll}
\hline Iopamidol & & & \\
\hline Gas & $\mathrm{C}=-0.0002 \mathrm{~T}^{2}+0.3841 \mathrm{~T}+28.257$ & $\mathrm{~S}=-0.0001 \mathrm{~T}^{2}+0.5054 \mathrm{~T}+106.3$ & $\mathrm{H}=9 \mathrm{E}-05 \mathrm{~T}^{2}+0.0865 \mathrm{~T}-9.6639$ \\
& $\mathrm{R}^{2}=0.9996$ & $\mathrm{R}^{2}=0.9997$ & $\mathrm{R}^{2}=0.9998$ \\
Chloroform & $\mathrm{C}=-0.0002 \mathrm{~T}^{2}+0.3846 \mathrm{~T}+28.184$ & $\mathrm{~S}=-0.0001 \mathrm{~T}^{2}+0.5085 \mathrm{~T}+101.17$ & $\mathrm{H}=9 \mathrm{E}-05 \mathrm{~T}^{2}+0.0866 \mathrm{~T}-9.7776$ \\
& $\mathrm{R}^{2}=0.9996$ & $\mathrm{R}^{2}=0.9999$ & $\mathrm{R}^{2}=0.9998$ \\
Acetic acid & $\mathrm{C}=-0.0001 \mathrm{~T}^{2}+0.3412 \mathrm{~T}+41.995$ & $\mathrm{~S}=-9 \mathrm{E}-05 \mathrm{~T}^{2}+0.44 \mathrm{~T}+122.2$ & $\mathrm{H}=0.0001 \mathrm{~T}^{2}+0.0712 \mathrm{~T}-4.8992$ \\
& $\mathrm{R}^{2}=0.996$ & $\mathrm{R}^{2}=0.9977$ & $\mathrm{R}^{2}=0.999$ \\
Ethanol & $\mathrm{C}=-0.0002 \mathrm{~T}^{2}+0.362 \mathrm{~T}+31.162$ & $\mathrm{~S}=-0.0001 \mathrm{~T}^{2}+0.4743 \mathrm{~T}+105.21$ & $\mathrm{H}=6 \mathrm{E}-05 \mathrm{~T}^{2}+0.1283 \mathrm{~T}-14.295$ \\
& $\mathrm{R}^{2}=0.9997$ & $\mathrm{R}^{2}=0.9999$ & $\mathrm{R}=0.999$ \\
DMF & $\mathrm{C}=-0.0002 \mathrm{~T}^{2}+0.3847 \mathrm{~T}+28.152$ & $\mathrm{~S}=-0.0001 \mathrm{~T}^{2}+0.5086 \mathrm{~T}+99.937$ & $\mathrm{H}=9 \mathrm{E}-05 \mathrm{~T}^{2}+0.0867 \mathrm{~T}-9.8173$ \\
& $\mathrm{R}^{2}=0.9996$ & $\mathrm{R}^{2}=0.9999$ & $\mathrm{R}=0.9998$ \\
DMSO & $\mathrm{C}=-0.0002 \mathrm{~T}^{2}+0.4077 \mathrm{~T}+19.679$ & $\mathrm{~S}=-0.0001 \mathrm{~T}^{2}+0.5129 \mathrm{~T}+98.095$ & $\mathrm{H}=8 \mathrm{E}-05 \mathrm{~T}^{2}+0.1063 \mathrm{~T}-14.192$ \\
& $\mathrm{R}^{2}=0.9988$ & $\mathrm{R}^{2}=0.9999$ & $\mathrm{R}^{2}=0.9997$ \\
Water & $\mathrm{C}=-0.0002 \mathrm{~T}^{2}+0.3917 \mathrm{~T}+26.68$ & $\mathrm{~S}=-0.0001 \mathrm{~T}^{2}+0.5086 \mathrm{~T}+99.973$ & $\mathrm{H}=9 \mathrm{E}-05 \mathrm{~T}^{2}+0.0828 \mathrm{~T}-9.2518$ \\
& $\mathrm{R}^{2}=0.9997$ & $\mathrm{R}^{2}=0.9999$ & $\mathrm{R}^{2}=0.9998$ \\
\hline
\end{tabular}

the methods of DFT/LANL2DZ level. The correlation equations between heat capacities, entropies, enthalpy changes and temperatures were fitted by quadratic formulas, and the corresponding fitting factors (R2) for these thermodynamic properties are $0.9996,0.9997$, and 0.9998 respectively for gas-phase; $0.9996,0.9999,0.9998$ respectively for chloroform. All the thermodynamic data supply helpful information for further study on the Iopamidol. All thermodynamic calculations were done in the gas phase in solution such as chloroform, acetic acid, ethanol, DMF, DMSO, water.

The net atomic charges of the Iopamidol contrast agent in various solvents using the Mulliken Population Analysis (MPA) method were given in Table 6. MPA values in different solvents were evidence of charge transfer and polarization. ${ }^{43}$. The significant influences of the sol- vents on the atomic charges are observed from the calculation. As seen from Table 6, the atomic charges increase with the increase of solvent polarity from acetone to water.

All carbon atoms making a bond with iodine atom in the benzene ring have a negative charge and the negative charge of the carbon atom bonded iodine atom increase with the increase of polarity of the solvent. The charge of $\mathrm{C}_{19}$ atom of Iopamidol in gas, chloroform, acetic acid, ethanol, DMF, DMSO, and water phases is $-0.7531,-0.7667$, $-0.7680,-0.7711,-0.7715,-0.7717,-0.7719 \bar{e}$. The rest of the carbon atoms in the benzene ring have positive excess charges accumulation and the positive charge of the carbon atom in the benzene ring increase with the increase of polarity of the solvent. The charges of nitrogen atoms are the negative and negative value of the charge decreases with the increase of polarity of the solvent. The charge of 

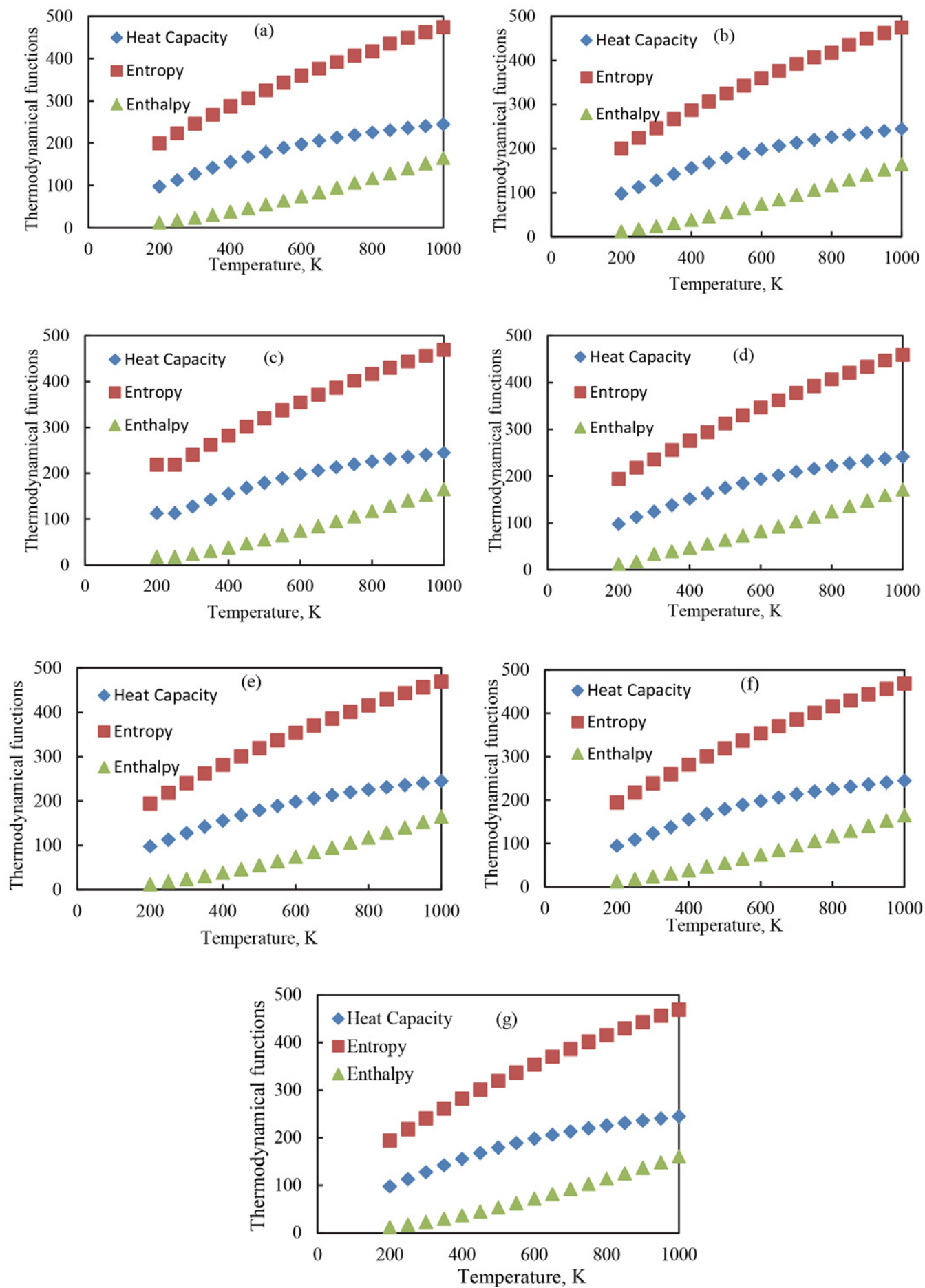

Figure 3. Correlation graph of heat capacity, entropy and enthalpy with temperature for Iopamidol molecule

$\mathrm{N}_{12}$ atom of Iopamidol in gas, chloroform, acetic acid, ethanol, DMF, DMSO, and the water phase is -0.3366 , $-0.3298,-0.3293,-0.3280,-0.3278,-0.3278,-0.3277$ e. The charge of $\mathrm{N}_{13}$ atom is $-0.3473,-0.3406,-0.3397$, $-0.3376,-0.3373,-0.3372,-0.3371$ è. All oxygen atoms belonging to the hydroxyl group and carbonyl group for Iopamidol have neagative charge, and the negative charge of both oxygen atoms increases with the increase of polarity of the solvent.

Selected second-order perturbation energies (E (2) $\mathrm{kcal} / \mathrm{mol}$ ) with values greater than $5 \mathrm{kcal} / \mathrm{mol}$

for Iopamidol in gas phase were presented in Table 7 , and Table 8 includes only energies for the other studied solvents and gas phase. The energies for the interaction 
Table 6. Some Mulliken Atomic charges (e) of Iopamidol in various solvents.

\begin{tabular}{|c|c|c|c|c|c|c|c|}
\hline & Gas & Chloroform & Acetic acid & Ethanol & DMF & DMSO & Water \\
\hline $\mathrm{I}_{1}$ & 0.1672 & 0.1899 & 0.1919 & 0.1970 & 0.1976 & 0.1978 & 0.1982 \\
\hline $\mathrm{I}_{2}$ & 0.1792 & 0.1868 & 0.1878 & 0.1904 & 0.1907 & 0.1909 & 0.1911 \\
\hline $\mathrm{I}_{3}$ & 0.1704 & 0.1910 & 0.1927 & 0.1967 & 0.1972 & 0.1974 & 0.1977 \\
\hline $\mathrm{O}_{4}$ & -0.5147 & -0.5337 & -0.5353 & -0.5390 & -0.5394 & -0.5396 & -0.5398 \\
\hline $\mathrm{O}_{5}$ & -0.4972 & -0.5264 & -0.5290 & -0.5352 & -0.5359 & -0.5363 & -0.5367 \\
\hline $\mathrm{O}_{6}$ & -0.4761 & -0.5177 & -0.5210 & -0.5290 & -0.5299 & -0.5303 & -0.5309 \\
\hline $\mathrm{O}_{7}$ & -0.5135 & -0.5409 & -0.5428 & -0.5473 & -0.5479 & -0.5481 & -0.5484 \\
\hline $\mathrm{O}_{8}$ & -0.3082 & -0.3494 & -0.3529 & -0.3616 & -0.3626 & -0.3630 & -0.3636 \\
\hline $\mathrm{O}_{9}$ & -0.2577 & -0.3129 & -0.3176 & -0.3290 & -0.3303 & -0.3309 & -0.3317 \\
\hline $\mathrm{O}_{10}$ & -0.5047 & -0.5291 & -0.5307 & -0.5343 & -0.5347 & -0.5348 & -0.5351 \\
\hline $\mathrm{O}_{11}$ & -0.2612 & -0.3174 & -0.3220 & -0.3330 & -0.3343 & -0.3349 & -0.3357 \\
\hline $\mathrm{N}_{12}$ & -0.3366 & -0.3298 & -0.3293 & -0.3280 & -0.3278 & -0.3278 & -0.3277 \\
\hline $\mathrm{N}_{13}$ & -0.3473 & -0.3406 & -0.3397 & -0.3376 & -0.3373 & -0.3372 & -0.3371 \\
\hline $\mathrm{N}_{14}$ & -0.5198 & -0.5101 & -0.5092 & -0.5068 & -0.5065 & -0.5064 & -0.5062 \\
\hline $\mathrm{C}_{17}$ & 0.5775 & 0.5957 & 0.5971 & 0.6001 & 0.6004 & 0.6005 & 0.6007 \\
\hline $\mathrm{C}_{18}$ & 0.5511 & 0.5666 & 0.5679 & 0.5710 & 0.5714 & 0.5715 & 0.5718 \\
\hline $\mathrm{C}_{19}$ & -0.7531 & -0.7667 & -0.7680 & -0.7711 & -0.7715 & -0.7717 & -0.7719 \\
\hline $\mathrm{C}_{20}$ & 0.8067 & 0.8134 & 0.8139 & 0.8153 & 0.8155 & 0.8155 & 0.8156 \\
\hline $\mathrm{C}_{21}$ & -0.7098 & -0.7287 & -0.7303 & -0.7343 & -0.7348 & -0.7350 & -0.7353 \\
\hline $\mathrm{C}_{22}$ & -0.7149 & -0.7283 & -0.7296 & -0.7325 & -0.7328 & -0.7330 & -0.7332 \\
\hline
\end{tabular}

Table 7. Selected second-order perturbation energy (E (2) kcal/mol) with values greater than $10 \mathrm{kcal} / \mathrm{mol}$ (except for iodine interaction) for Iopamidol in gas phase.

\begin{tabular}{|c|c|c|c|c|c|c|c|c|c|c|}
\hline Donor (i) & Type & Occupancy & $\mathrm{ED}(\mathrm{j})$ & Acceptor & Type & Occupancy & $\mathbf{E D}(\mathbf{j}$ & $\begin{array}{c}\mathrm{E}(2) \\
\mathrm{kcal} / \mathrm{mol}\end{array}$ & $\begin{array}{c}\mathrm{E}(\mathbf{j})-\mathrm{E}(\mathbf{i}) \\
\mathbf{a} \cdot \mathbf{u}\end{array}$ & $\begin{array}{c}F(\mathbf{i}, \mathbf{j}) \\
\mathbf{a . u}\end{array}$ \\
\hline $\mathrm{C}_{17}-\mathrm{C}_{22}$ & $\pi$ & 1.67185 & -0.74673 & $\mathrm{C}_{18}-\mathrm{C}_{19}$ & $\pi^{*}$ & 0.39117 & -0.00725 & 18.95 & 0.29 & 0.067 \\
\hline $\mathrm{C}_{17}-\mathrm{C}_{22}$ & $\pi$ & 1.67185 & -0.74673 & $\mathrm{C}_{20}-\mathrm{C}_{21}$ & $\pi^{*}$ & 0.39095 & -0.00959 & 22.39 & 0.29 & 0.073 \\
\hline $\mathrm{C}_{18}-\mathrm{C}_{19}$ & $\pi$ & 1.67060 & -0.29565 & $\mathrm{C}_{17}-\mathrm{C}_{22}$ & $\pi^{*}$ & 0.39611 & -0.00844 & 23.39 & 0.29 & 0.074 \\
\hline $\mathrm{C}_{18}-\mathrm{C}_{19}$ & $\pi$ & 1.67060 & -0.29565 & $\mathrm{C}_{20}-\mathrm{C}_{21}$ & $\pi^{*}$ & 0.39095 & -0.00959 & 19.16 & 0.29 & 0.067 \\
\hline $\mathrm{C}_{20}-\mathrm{C}_{21}$ & $\pi$ & 1.65835 & -0.29446 & $\mathrm{C}_{17}-\mathrm{C}_{22}$ & $\pi^{*}$ & 0.39611 & -0.00844 & 19.73 & 0.29 & 0.068 \\
\hline $\mathrm{C}_{20}-\mathrm{C}_{21}$ & $\pi$ & 1.65835 & -0.29446 & $\mathrm{C}_{18}-\mathrm{C}_{19}$ & $\pi^{*}$ & 0.39117 & -0.00725 & 23.60 & 0.29 & 0.074 \\
\hline $\mathrm{I}_{1}$ & LP3 & 1.94231 & -0.27742 & $\mathrm{C}_{18}-\mathrm{C}_{19}$ & $\pi *$ & 0.39117 & -0.00725 & 7.31 & 0.27 & 0.043 \\
\hline $\mathrm{I}_{2}$ & LP3 & 1.93293 & -0.26730 & $\mathrm{C}_{20}-\mathrm{C}_{21}$ & $\pi *$ & 0.39095 & -0.00959 & 7.83 & 0.26 & 0.044 \\
\hline $\mathrm{I}_{3}$ & LP3 & 1.93545 & -0.27219 & $\mathrm{C}_{17}-\mathrm{C}_{22}$ & $\pi^{*}$ & 0.39611 & -0.00844 & 7.81 & 0.26 & 0.044 \\
\hline $\mathrm{O}_{8}$ & LP2 & 1.86415 & -0.29057 & $\mathrm{~N}_{12}-\mathrm{C}_{23}$ & $\sigma *$ & 0.06954 & 0.42301 & 16.06 & 0.71 & 0.097 \\
\hline $\mathrm{O}_{8}$ & LP2 & 1.86415 & -0.29057 & $\mathrm{C}_{17}-\mathrm{C}_{23}$ & $\sigma^{*}$ & 0.06831 & 0.35615 & 18.75 & 0.65 & 0.100 \\
\hline $\mathrm{O}_{9}$ & LP2 & 1.86542 & -0.25360 & $\mathrm{~N}_{13}-\mathrm{C}_{24}$ & $\sigma *$ & 0.07259 & 0.42608 & 21.11 & 0.68 & 0.109 \\
\hline $\mathrm{O}_{9}$ & LP2 & 1.86542 & -0.25360 & $\mathrm{C}_{18}-\mathrm{C}_{24}$ & $\sigma *$ & 0.07486 & 0.35976 & 19.38 & 0.61 & 0.099 \\
\hline $\mathrm{O}_{11}$ & LP2 & 1.87731 & -0.25037 & $\mathrm{~N}_{14}-\mathrm{C}_{29}$ & $\sigma^{*}$ & 0.07966 & 0.41160 & 23.83 & 0.66 & 0.113 \\
\hline $\mathrm{O}_{11}$ & LP2 & 1.87731 & -0.25037 & $\mathrm{C}_{29^{-}}-\mathrm{C}_{30}$ & $\sigma *$ & 0.08219 & 0.33581 & 19.06 & 0.59 & 0.095 \\
\hline $\mathrm{N}_{12}$ & LP1 & 1.65078 & -0.27471 & $\mathrm{O}_{8}-\mathrm{C}_{23}$ & $\sigma^{*}$ & 0.20853 & 0.18886 & 24.37 & 0.46 & 0.098 \\
\hline $\mathrm{N}_{12}$ & LP1 & 1.65078 & -0.27471 & $\mathrm{O}_{8}-\mathrm{C}_{23}$ & $\pi *$ & 0.17216 & 0.23265 & 12.69 & 0.51 & 0.075 \\
\hline $\mathrm{N}_{13}$ & LP1 & 1.66817 & -0.26134 & $\mathrm{O}_{9}-\mathrm{C}_{24}$ & $\sigma^{*}$ & 0.25871 & 0.09976 & 39.60 & 0.36 & 0.109 \\
\hline $\mathrm{N}_{14}$ & LP1 & 1.66817 & -0.26134 & $\mathrm{O}_{11}-\mathrm{C}_{29}$ & $\pi *$ & 0.21432 & 0.10625 & 33.67 & 0.38 & 0.103 \\
\hline
\end{tabular}

LP3 $\left(\mathrm{I}_{1}\right) \rightarrow \pi^{\star}\left(\mathrm{C}_{18}-\mathrm{C}_{19}\right), \mathrm{LP} 3\left(\mathrm{I}_{2}\right) \rightarrow \pi^{*}\left(\mathrm{C}_{20}-\mathrm{C}_{21}\right)$ and LP3 $\left(\mathrm{I}_{3}\right)$ $\rightarrow \pi^{*}\left(\mathrm{C}_{17}-\mathrm{C}_{22}\right) 7.31,7.83$ and $7.81 \mathrm{kcal} \mathrm{mol}^{-1}$, respectively demonstrate the intramolecular hyperconjugative interaction between the iodine atoms and benzene ring in the ground state for Iopamidol in gas phase.

The interaction energy from the $\mathrm{I}_{1}$ electron pairs corresponds to conjugation with the antibonding molecular orbitals of the neighboring $\mathrm{C}_{20}-\mathrm{C}_{21}$ whereas, these interac- tion energies correspond to conjugation with the antibonding molecular orbitals of the neighboring LP3 $\left(\mathrm{I}_{1}\right) \rightarrow$ $\pi^{\star} \mathrm{C}_{17}-\mathrm{C}_{19}$ with the stabilization energy $7.41,7.42,7.43$ $\mathrm{kcal} / \mathrm{mol}$ in chloroform, acetic acid, and ethanol, respectively, and $7.44 \mathrm{kcal} / \mathrm{mol}$ in DMF, DMSO, water. The interaction $\mathrm{LP} 3\left(\mathrm{I}_{2}\right) \rightarrow \pi^{*}\left(\mathrm{C}_{20}-\mathrm{C}_{21}\right)$ in gas phase shifted to $\mathrm{LP} 3\left(\mathrm{I}_{2}\right)$ $\rightarrow \pi^{\star}\left(\mathrm{C}_{18}-\mathrm{C}_{21}\right)$ in studied solvents and LP3 $\left(\mathrm{I}_{3}\right) \rightarrow \pi^{\star}\left(\mathrm{C}_{17}-\mathrm{C}_{22}\right)$ was shifted to $\mathrm{LP} 3\left(\mathrm{I}_{3}\right) \rightarrow \pi^{*}\left(\mathrm{C}_{20}-\mathrm{C}_{22}\right)$ in studied solvents. 
Table 8. Interaction energies of Iopamidol in gas phase and in different solvents.

\begin{tabular}{|c|c|c|c|c|c|c|c|c|c|c|}
\hline Donor & Type & Acceptor & Type & $\begin{array}{l}\text { Gas } \\
\mathrm{E}(2) \mathrm{kcal} / \mathrm{mol}\end{array}$ & Chloroform & Acetic Acid & Ethanol & DMF & DMSO & Water \\
\hline $\mathrm{I}_{1}-\mathrm{C}_{19}$ & $\sigma$ & $\mathrm{C}_{17}-\mathrm{C}_{22}$ & $\sigma^{*}$ & 7.06 & 7.10 & 7.11 & 7.12 & 7.12 & 7.12 & 7.12 \\
\hline $\mathrm{I}_{1}-\mathrm{C}_{19}$ & $\sigma$ & $\mathrm{C}_{18}-\mathrm{C}_{21}$ & $\sigma^{\star}$ & 7.07 & 7.05 & 7.05 & 7.06 & 7.06 & 7.06 & 7.06 \\
\hline $\mathrm{I}_{2}-\mathrm{C}_{21}$ & $\sigma$ & $\mathrm{C}_{18}-\mathrm{C}_{19}$ & $\sigma^{*}$ & 7.15 & 7.16 & 7.16 & 7.16 & 7.17 & 7.17 & 7.17 \\
\hline $\mathrm{I}_{2}-\mathrm{C}_{21}$ & $\sigma$ & $\mathrm{C}_{20}-\mathrm{C}_{22}$ & $\sigma^{*}$ & 7.12 & 7.19 & 7.19 & 7.21 & 7.21 & 7.21 & 7.21 \\
\hline $\mathrm{I}_{3}-\mathrm{C}_{22}$ & $\sigma$ & $\mathrm{C}_{17}-\mathrm{C}_{19}$ & $\sigma^{*}$ & 7.11 & 7.17 & 7.39 & 7.19 & 7.19 & 7.19 & 7.19 \\
\hline $\mathrm{I}_{3}-\mathrm{C}_{22}$ & $\sigma$ & $\mathrm{C}_{20}-\mathrm{C}_{21}$ & $\sigma^{*}$ & 7.13 & 7.21 & 7.22 & 7.23 & 7.24 & 7.24 & 7.24 \\
\hline $\mathrm{C}_{17}-\mathrm{C}_{19}$ & $\pi$ & $\mathrm{C}_{18}-\mathrm{C}_{21}$ & $\pi^{*}$ & & 22.60 & 22.58 & 22.53 & 22.53 & 22.53 & 22.52 \\
\hline $\mathrm{C}_{17}-\mathrm{C}_{19}$ & $\pi$ & $\mathrm{C}_{20}-\mathrm{C}_{22}$ & $\pi^{*}$ & & 19.17 & 19.17 & 19.17 & 19.17 & 19.17 & 19.17 \\
\hline $\mathrm{C}_{17}-\mathrm{C}_{22}$ & $\pi$ & $\mathrm{C}_{18}-\mathrm{C}_{19}$ & $\pi^{*}$ & 18.95 & & & & & & \\
\hline $\mathrm{C}_{17}-\mathrm{C}_{22}$ & $\pi$ & $\mathrm{C}_{20}-\mathrm{C}_{21}$ & $\pi^{*}$ & 22.39 & & & & & & \\
\hline $\mathrm{C}_{18}-\mathrm{C}_{19}$ & $\pi$ & $\mathrm{C}_{17}-\mathrm{C}_{22}$ & $\pi^{*}$ & 23.39 & & & & & & \\
\hline $\mathrm{C}_{18}-\mathrm{C}_{19}$ & $\pi$ & $\mathrm{C}_{20}-\mathrm{C}_{21}$ & $\pi^{*}$ & 19.16 & & & & & & \\
\hline $\mathrm{C}_{18}-\mathrm{C}_{21}$ & $\pi$ & $\mathrm{C}_{17}-\mathrm{C}_{19}$ & $\pi^{*}$ & & 19.64 & 19.64 & 19.63 & 19.63 & 19.63 & 19.63 \\
\hline $\mathrm{C}_{18}-\mathrm{C}_{21}$ & $\pi$ & $\mathrm{C}_{20}-\mathrm{C}_{22}$ & $\pi^{*}$ & & 22.71 & 22.67 & 22.60 & 22.59 & 22.59 & 22.58 \\
\hline $\mathrm{C}_{18}-\mathrm{C}_{24}$ & $\sigma$ & $\mathrm{N}_{13}-\mathrm{C}_{16}$ & $\sigma^{*}$ & & 6.25 & 6.26 & 6.29 & 6.30 & 6.30 & 6.30 \\
\hline $\mathrm{C}_{20}-\mathrm{C}_{21}$ & $\pi$ & $\mathrm{C}_{17}-\mathrm{C}_{22}$ & $\pi^{*}$ & 19.73 & & & & & & \\
\hline $\mathrm{C}_{20}-\mathrm{C}_{21}$ & $\pi$ & $\mathrm{C}_{17}-\mathrm{C}_{19}$ & $\pi^{*}$ & 23.60 & & 23.53 & 23.53 & 23.53 & 23.53 & 23.53 \\
\hline $\mathrm{C}_{20}-\mathrm{C}_{22}$ & $\pi$ & $\mathrm{C}_{18}-\mathrm{C}_{21}$ & $\pi^{*}$ & & 23.53 & 19.52 & 19.61 & 19.62 & 19.62 & 19.63 \\
\hline $\mathrm{C}_{20}-\mathrm{C}_{22}$ & $\pi$ & $\mathrm{C}_{18}-\mathrm{C}_{19}$ & $\pi^{*}$ & & 19.48 & & & & & \\
\hline $\mathrm{I}_{1}$ & LP3 & $\mathrm{C}_{17}-\mathrm{C}_{19}$ & $\pi^{*}$ & & 7.41 & 7.42 & 7.43 & 7.44 & 7.44 & 7.44 \\
\hline $\mathrm{I}_{1}$ & LP3 & $\mathrm{C}_{18}-\mathrm{C}_{19}$ & $\pi^{*}$ & 7.31 & & & & & & \\
\hline $\mathrm{I}_{2}$ & LP3 & $\mathrm{C}_{18}-\mathrm{C}_{21}$ & $\pi^{*}$ & & 7.90 & 7.90 & 7.90 & 7.90 & 7.90 & 7.90 \\
\hline $\mathrm{I}_{2}$ & LP3 & $\mathrm{C}_{20}-\mathrm{C}_{21}$ & $\pi^{*}$ & 7.83 & & & & & & \\
\hline $\mathrm{I}_{3}$ & LP3 & $\mathrm{C}_{17}-\mathrm{C}_{22}$ & $\pi^{*}$ & 7.81 & & & & & & \\
\hline $\mathrm{I}_{3}$ & LP3 & $\mathrm{C}_{20}-\mathrm{C}_{22}$ & $\pi^{*}$ & & 7.65 & 7.66 & 7.69 & 7.69 & 7.69 & 7.69 \\
\hline $\mathrm{O}_{8}$ & LP2 & $\mathrm{O}_{5}-\mathrm{H}_{47}$ & $\sigma^{*}$ & 9.35 & 14.20 & 14.52 & 15.38 & 15.48 & 15.52 & 15.59 \\
\hline $\mathrm{O}_{8}$ & LP2 & $\mathrm{N}_{12}-\mathrm{C}_{23}$ & $\sigma^{*}$ & 16.06 & 13.76 & 13.59 & 13.17 & 13.12 & 13.10 & 13.06 \\
\hline $\mathrm{O}_{8}$ & LP2 & $\mathrm{C}_{17}-\mathrm{C}_{23}$ & $\sigma^{*}$ & 18.75 & 18.21 & 18.14 & 17.97 & 17.95 & 17.94 & 17.93 \\
\hline $\mathrm{O}_{9}$ & LP2 & $\mathrm{N}_{13}-\mathrm{C}_{24}$ & $\sigma^{*}$ & 21.11 & 20.05 & 19.96 & 19.74 & 19.72 & 19.71 & 19.69 \\
\hline $\mathrm{O}_{9}$ & LP2 & $\mathrm{C}_{18}-\mathrm{C}_{24}$ & $\sigma^{*}$ & 19.38 & 18.35 & 18.26 & 18.05 & 18.03 & 18.02 & 18.00 \\
\hline $\mathrm{O}_{11}$ & LP2 & $\mathrm{N}_{14}-\mathrm{C}_{29}$ & $\sigma^{*}$ & 23.83 & 22.61 & 22.51 & 22.27 & 22.24 & 22.23 & 22.21 \\
\hline $\mathrm{O}_{11}$ & LP2 & $\mathrm{C}_{29}-\mathrm{C}_{30}$ & $\sigma^{*}$ & 19.06 & 18.02 & 17.93 & 17.72 & 17.70 & 17.69 & 17.67 \\
\hline $\mathrm{N}_{12}$ & LP1 & $\mathrm{O}_{8}-\mathrm{C}_{23}$ & $\sigma^{*}$ & 24.37 & 72.52 & 75.67 & 82.43 & 83.14 & 83.44 & 83.90 \\
\hline $\mathrm{N}_{12}$ & LP1 & $\mathrm{O}_{8}-\mathrm{C}_{23}$ & $\pi^{*}$ & 12.69 & & & & & & \\
\hline $\mathrm{N}_{13}$ & LP1 & $\mathrm{O}_{9}-\mathrm{C}_{24}$ & $\sigma^{*}$ & 39.60 & 81.88 & 83.09 & 85.07 & 85.29 & 85.37 & 85.50 \\
\hline $\mathrm{N}_{14}$ & LP1 & $\mathrm{O}_{11}-\mathrm{C}_{29}$ & $\sigma^{*}$ & & 15.95 & 17.47 & 21.64 & 22.15 & 22.37 & 22.73 \\
\hline $\mathrm{N}_{14}$ & LP1 & $\mathrm{O}_{11}-\mathrm{C}_{29}$ & $\pi^{*}$ & 33.67 & 16.10 & 14.84 & 12.02 & 11.73 & 11.61 & 11.41 \\
\hline
\end{tabular}

The stabilization energy for the interaction $\mathrm{LP} 1\left(\mathrm{O}_{8}\right) \rightarrow$ $\sigma^{\star}\left(\mathrm{N}_{12}-\mathrm{C}_{23}\right)$ and $\mathrm{LP} 2\left(\mathrm{O}_{8}\right) \rightarrow \sigma^{\star}\left(\mathrm{O}_{5}-\mathrm{H}_{47}\right)$ increases with the increase of the dielectric constant of the solvent whereas the stabilization energy for the interaction $\mathrm{LP} 2\left(\mathrm{O}_{8}\right) \rightarrow$ $\sigma^{\star}\left(\mathrm{N}_{12}-\mathrm{C}_{23}\right)$ and LP2 $\left(\mathrm{O}_{8}\right) \rightarrow \sigma^{*}\left(\mathrm{C}_{17}-\mathrm{C}_{23}\right)$ decreases with the increase of the dielectric constant of the solvent.

\section{Conclusions}

The ground state molecular geometries, polarizability, anisotropic polarizability, hyperpolarizability, and frontier orbital energies of Iopamidol were theoretically investigated in gas, chloroform, acetic a4cid, ethanol, DMF, DMSO, and water phase to understand the structureproperty relationship of the molecular structure of Iopamidol in terms of solvent effects.
From the obtained results by using the DFT calculations, it was obtained that the dipole moment, electrophilicity index, polarizability and first-order hyperpolarizability of Iopamidol was gradually increased with the increase of dielectric constant of the solvent.

Likewise, the largest HOMO-LUMO gap was found in water solvent and this means higher kinetic stability and less chemical reactivity with increasing polarity of solvents. Therefore, quantum chemical calculations aid the understanding of the structure- property relationship of molecules.

Solvent effects on thermodynamic properties of the optimized geometry of the molecule were investigated and reported. The variation of solvent influences the structural, electronic, and molecular properties of the Iopamidol and will be useful in the design and development of Iopamidol as a contrast agent. 
The NBO analysis has provided a detailed in-sight into the type of hybridization and the nature of bonding in Iopamidol. he stabilization energy for the interaction $\mathrm{LP} 1\left(\mathrm{O}_{8}\right) \rightarrow \sigma^{\star}\left(\mathrm{N}_{12}-\mathrm{C}_{23}\right)$ increases with the increase of the dielectric constant of the solvent whereas the stabilization energy for the interaction $\mathrm{LP} 2\left(\mathrm{O}_{8}\right) \rightarrow \sigma^{\star}\left(\mathrm{N}_{12}-\mathrm{C}_{23}\right)$ decreases with the increase of the dielectric constant of the solvent. The negative charge of carbon atoms attached to the iodine atom in the benzene ring increase with the increase of polarity of the solvent. The rest of the carbon atoms in the benzene ring have positive and positive charge density with the increase of polarity of the solvent.

\section{References}

1. F. M. Wendel, C. L. Eversloh, E. J. Machek, S. E. Duirk, M. J. Plewa, S.D. Richardson, T.A. Ternes, Environ. Sci. Technol, 2014, 48, 12689-12697. DOI:10.1021/es503609s

2. M. R. Karim, L. Balsam and S. Rubinstein, Am. J. Kidney Dis., 2010, 55(4), 712-716. DOI:10.1053/j.ajkd.2009.08.016

3. H. Dib, K. Agan, I. Midi, C. A. Bingöl, The Internet J. Neurol., 2008, 11(1), 1-3. DOI:10.5580/1a64

4. S. Aime, L. Calabi, L. Biondi, M. De Miranda, S. Ghelli, L. Paleari, C. Rebaudengo, E. Terreno, Magn. Reson. Med., 2005, 53, 830-834. DOI:10.1002/mrm.20441

5. D. L. Longo, W. Dastru, G. Digilio, J. Keupp, S. Langereis, S. Lanzardo, S. Prestigio, O. Steinbach, E. Terreno, F. Uggeri, S. Aime, Magn. Reson. Med., 2011, 65, 202-211.

DOI: $10.1002 / \mathrm{mrm} .22608$

6. P. L. Praveen, D. P Ojha, Cryst. Res. Technol., 2012, 47, 91100. DOI:10.1002/crat.201100481

7. M. F. Khan, R. B. Rashid, S. M. Islam, M. A. Rashid, SQU. J. Sci., 2016, 21, 89-101. DOI:10.24200/squjs.vol21iss2pp89-101

8. M. Targema, N. O. Obi-Egbedi, M. D. Adeoye, Comput. Theor. Chem., 2013, 1012, 47-53.

DOI:10.1016/j.comptc.2013.02.020

9. S. G. Zhang, W. Lei, M. Z. Xia, F. Y. Wang, J. Mol. Struct. (THEOCHEM), 2005, 732, 173-182.

DOI:10.1016/j.theochem.2005.02.091

10. B. Bellich, S. Di Fonzo, L. Tavagnacco, M. Paolantoni, C. Masciovecchio, F. Bertolotti, G. Giannini, R. De Zorzi, S. Geremia, A. Maiocchi, F. Uggeri, N. Masciocchi, A. Cesàro, Mol. Pharmaceutics, 2017, 14(2), 468-477.

DOI:10.1021/acs.molpharmaceut.6b00902

11. P. Sun, G. Y. Yang, H. X. Liu, Z. Y. Wang, J. Chem. Eng. Data, 2009, 54, 2404-2410. DOI:10.1021/je8008304

12. Y. Wang, X. L. Zeng, H. J. Chen, H. J. Wang, J. Chem. Eng. Data, 2007, 52, 1442-1448. DOI:10.1021/je700127w

13. B. G. Johnson, P. M. W. Gill, J. A. Pople, J. Chem. Phys. 1993, 98(7), 5612-5626. DOI:10.1063/1.464906

14. N. C. Handy, C. W. Murray, R. D. Amos, J. Phys. Chem., 1993, 97(17), 4392-4396. DOI:10.1021/j100119a023

15. X. F. Zhou, J. A. Krauser, D. R. Tate, A. S. Vanburen, J. Phys. Chem., 1996, 100(42), 16822-16827.

DOI:10.1021/jp960170r
16. M. J.Frisch, G. W.Trucks, H. B. Schlegel, G. E. Scuseria, M. A. Robb, J. R. Cheeseman, G. Scalmani, V. Barone, B. Mennucci, G. A. Petersson, H. Nakatsuji, M. Caricato, X. Li, H. P. Hratchian, A. F. Izmaylov, J. Bloino, G. Zheng, J. L. Sonnenberg, M. Hada, M. Ehara, K. Toyota, R. Fukuda, J. Hasegawa, M. Ishida, T. Nakajima, Y. Honda, O. Kitao, H. Nakai, T. Vreven, J. A. Montgomery, Jr. J. E. Peralta, F. Ogliaro, M. Bearpark, J. J. Heyd, E. Brothers, K. N. Kudin, V. N. Staroverov, R. Kobayashi, J. Normand, K. Raghavachari, A. Rendell, J. C. Burant, S. S. Iyengar, J. Tomasi, M. Cossi, N. Rega, J. M. Millam, M. Klene, J. E. Knox, J. B. Cross, V. Bakken, C. Adamo, J. Jaramillo, R. Gomperts, R. E. Stratmann, O. Yazyev, A. J. Austin, R. Cammi, C. Pomelli, J. W. Ochterski, R. L. Martin, K. Morokuma, V. G. Zakrzewski, G. A. Voth, P. Alvador, J. J. Dannenberg, S. Dapprich, A. D. Daniels, Ö. Farkas, J. B. Foresman, J. V. Ortiz, J. Cioslowski, D. J. Fox, Gaussian Inc., Wallingford CT, 2009.

17. T. H. Dunning Jr., P .J. Hay, in Modern Theoretical Chemistry, (Ed.): H. F. Schaefer III, Plenum, New York, 1977, 3, 1-28.

18. P. Macak, Solvent and vibrational effects on nonlinear optical properties; Ph.D. thesis, Royal Institute of Technology: Stockholm, 2002.

19. I. Fleming, Frontier orbitals and organic chemical reaction. New York, NY: John Wiley and Sons, 1976.

20. K. Fukui, Science, 1982, 218, 747-754. DOI:10.1126/science.218.4574.747

21. S. G. Kandemirli, F. Genç, F. Kandemirli, M. Evecen, EJOSAT, 2020, 20, 351-359. DOI:10.31590/ejosat.732239

22. T. Abbaz, A. Benjeddou, D. Villemin, Pharm. Biol. Eval., 2018, 5(2), 27-39.

DOI:10.26510/2394-0859.pbe.2018.04

23. R. G. Parr, R.G. Pearson, J. Am. Chem. Soc., 1983, 105, 75127516. DOI:10.1021/ja00364a005

24. R. G. Parr, W. Yang, Density functional theory of atoms and molecules, Oxford University Press: New York, NY, USA, 1989.

25. T. Koopmans, Physica, 1934, 1, 104-113. DOI:10.1016/S0031-8914(34)90011-2

26. W. Kohn, L.J. Sham, Phys. Rev., B, 1965, 140, A1133-A1138. DOI:10.1103/PhysRev.140.A1133

27. L. R. Domingo, RSC Adv., 2014, 4, 32415-32428. DOI: $10.1039 / \mathrm{C} 4 \mathrm{RA} 04280 \mathrm{H}$

28. R. G. Pearson, J. Am. Chem. Soc., 1963, 85, 3533-3539. DOI:10.1021/ja00905a001

29. R. G. Pearson, Science, 1966, 151, 172-177. DOI:10.1126/science.151.3707.172

30. R. G. Pearson, J. Songstad, J. Am. Chem. Soc., 1967, 89, 18271836. DOI:10.1021/ja00984a014

31. L. R. Domingo, M. J. Aurell, P. Pérez, R. Contreras, Tetrahedron, 2002, 58, 4417-4423.

DOI:10.1016/S0040-4020(02)00410-6

32. Y. P. Semenyuk, P.G. Morozov, O.N. Burov, M. K. Kletskii, A. V. Lisovin, S. V. Kurbatov, F. Terrier, Tetrahedron, 2016, 72, 2254-2264. DOI:10.1016/j.tet.2016.03.024

33. R. G. Parr, L. von Szentpaly, S. Liu, J. Am. Chem. Soc., 1999, 121, 1922-1924. DOI:10.1021/ja983494x 
34. J. Padmanabhan, R. Parthasarathi, V. Subramaniaan, P. K. Chattaraj, J. Phys. Chem., 2007, 111, 1358-1361.

DOI:10.1021/jp0649549

35. R. G. Pearson, J. Org. Chem. 1989, 54, 1423-1430. DOI:10.1021/jo00267a034

36. R. G. Parr, W. Yang, J. Am. Chem. Soc., 1984, 106, 404. DOI:10.1021/ja00326a036

37. R. Ahmadi, M. Pirahan-Foroush, Ann. Mil. Health. Sci. Res. (AMHSR), 2014a, 12(2), 86-90.

38. P. W. Ayers, J. S. M. Anderson, L. J. Bartolotti, Int. J. Quantum Chem, 2005, 101, 520-534. DOI:10.1002/qua.20307
39. G. Roos, S. Loverix, E. Brosens, K. Van Belle, L. Wyns, P. Geerlings, J. Messens, ChemBioChem., 2006, 7, 981-989. DOI:10.1002/cbic.200500507

40. M. Grandi, D. Pitre, Biomed. Mass Spectrom., 1983, 10(1), 17-23. DOI:10.1002/bms.1200100105

41. H. Abdulaziz, A. S. Gidado, A. Musa, A. Lawal, J. Mater. Sci. Rev., 2019, 2(3), 1-13. DOI: 10.9734/JMSRR/2019/45683.

42. M. Govindarajan, M. Karabacak, Spectrochimica Acta Part A, 2012, 85, 251-260. DOI:10.1016/j.saa.2011.10.002

43. R. S. J. Mulliken, J. Chem. Phys., 1962, 36, 3428 . termodinamske lastnosti v območju 200-1000.

\section{Povzetek}

Neionske kontrastne snovi z nizko osmolalnostjo veljajo za varne pri intravenozni in intraarterialni aplikaciji. Iopamidol je eno od kontrastnih sredstev ki se uporablja za diagnostično računalniško tomografijo (CT) že štiri desetletja.

Molekulsko strukturo Iopamidola smo izračunali s funkcionalnim modelom B3LYP in baznim setom LANL2DZ določenim z Gaussovim programom. Analizo veznih orbital, hibridizacijo atomov in elektronsko strukturo molekule smo izvedli s podatki dobljenimi iz kvantno kemijskih izračunov. $\mathrm{V}$ članku podajamo vrednosti za hiperpolarizabilnost prvega reda $(\beta$ tot), dipolni moment $(\mu)$, polarizabilnost $(\alpha)$ in anizotropno polarizabilnost $(\Delta \alpha)$ molekule. Energije HOMO in LUMO in parametri povezani z energijami, dipolnim momentom, polarizabilnostjo in hiperpolarizabilnostjo so le malo odvisni od polarnosti topila. Trdota Iopamidola se zmanjšuje z naraščanjem polarnosti topila. Analizirali smo stabilnost kontrastnega sredstva Iopamidol s hiperkonjugativnimi interakcijami in izračunali K.

Except when otherwise noted, articles in this journal are published under the terms and conditions of the Creative Commons Attribution 4.0 International License 